http://jmscr.igmpublication.org/home/

ISSN (e)-2347-176x ISSN (p) 2455-0450

crossref DOI: https://dx.doi.org/10.18535/jmscr/v7i12.22

Journal Of Medical Science And Clinical Research

IGM Publication

An Official Publication of IGM Publication

\title{
Comparison of statin-induced myalgia between atorvastatin and rosuvastatin and among different duration of treatment groups: An observational study in a tertiary care hospital of West Bengal
}

\author{
Authors \\ Prof. Abhijit Das ${ }^{1}$, Samya Dutta ${ }^{2 *}$, Prof. Suhrita Paul ${ }^{3}$, Arpita Maitra ${ }^{4}$, \\ Shouvik Choudhury ${ }^{5}$ \\ ${ }^{1}$ Professor, ${ }^{2}$ Post Graduate Trainee, ${ }^{4}$ Assistant Professor, ${ }^{5}$ Senior Resident, \\ Department of Pharmacology, Burdwan Medical College, West Bengal \\ ${ }^{3}$ Professor of Pharmacology and Principal, Burdwan Medical College \\ *Corresponding Author \\ Samya Dutta
}

\section{Introduction}

Coronary heart disease (CHD) is a leading cause of cardiovascular morbidity and mortality worldwide. ${ }^{1}$ Even in India, a recent surge has been noticed in the prevalence of CHD (from 10.19\% in $1991-94$ to $13.91 \%$ in $2010-12$ ). ${ }^{2}$ The mainstay of pathogenesis of CHD fundamentally involves building up of atherosclerotic plaques inside the arterial wall which leads to narrowing of the arterial lumen and finally, diminished blood flow. The development of cholesterol plaques in the arterial walls has conventionally been linked to dyslipidemia. $^{3-7}$ Dyslipidemia is defined as irregularities in plasma concentration of cholesterol lipoprotein lipids, such as an elevated total cholesterol or increased low-density lipoprotein (LDL) or decreased concentration of high-density lipoprotein (HDL). Recent population based studies in India documented an increase in the prevalence of dyslipidemia in either gender and across all inhabitations and socio-economic strata. $^{8-11}$ Consequently, a significant portion of the Indian population faces a high risk of developing atherosclerosis and as a result, the incidence of cardiovascular morbidities may flare up in our country in the forthcoming years. $^{12}$

3-hydroxy-3-methylglutaryl coenzyme A reductase inhibitors (statins) have always remained the mainstay of pharmacotherapy for preventing atherosclerotic changes in the coronary arterial walls, unless found absolutely contraindicated in certain cases. Thus, their efficacy has been proved in primary and secondary prevention of cardiovascular diseases in several studies. ${ }^{13-15}$

However, notwithstanding the benefits attributed to this class of drugs, discontinuation of therapy is quite common in statin recipients. The key reason for such discontinuation often indicates towards the statin-induced myalgia, which is observed in nearly $10-15 \%$ of chronic statin users. ${ }^{15-27}$ The underlying mechanism of statin-induced myotoxicity may involve the fact that action of statins is not limited to liver cells but inhibits the mevalonate pathway in the muscle cells as well. 
This leads to reduction in isoprenoid synthesis, which is an essential component for differentiation of skeletal muscle cells. ${ }^{16}$ Alternative theories include altered behaviour of myocyte membranes due toimpairment of cholesterol synthesis ${ }^{17}$ or changes in ubiquitin proteasome pathwayaffecting gene expression. ${ }^{18}$ But whatever the mechanism may be,themajor concern always associated with statin-induced myalgia is the relative nonavailability of a proper diagnostic tool. Therefore, it relies mostly on the patient's as well as the physician's impression regarding the symptoms and if not properly taken care of, this may lead to spontaneous discontinuation of therapy. ${ }^{15}$ Such discontinuation of statin would always mean missing out on the beneficial effects of a drug that could significantly reduce the risk of cardiovascular diseases. $^{28-29}$

Despite the frequency of occurrence, not much is known about the variability of myalgia among different members of the statin family. Although some earlier studies could not point out a significant difference between atorvastatin and rosuvastatin $^{30}$, information available regarding this difference is still insufficient. Furthermore, these muscle-related adverse reactions are presumed to be gradually progressive in nature, but, little conclusive evidence is available regarding the relationship of statin-induced myalgia with duration of therapy.

As the threat of CHD escalates quickly, statins are being used more felicitously on the Indian patients with dyslipidemia. Nevertheless, data obtained from the Indian population regarding statininduced myalgia remains inadequate. As our population varies largely from the western counterparts largely due to environmental and genetic factors, inadequacy in assessment of muscle-related adverse reactions that are specific to the population can lead to an increased rate of discontinuation.

Therefore, a study was planned to detect and assess statin-induced myalgia on patients receiving atorvastatin or rosuvastatin in the Cardiology outdoor of Burdwan Medical College and Hospital (a tertiary care hospital of West Bengal) and who had already received statin therapy for a period of at least one month prior to the commencement of this study.

\section{Objectives}

Primary objective of this study was to assess the occurrence of muscle pain and other muscle related symptoms in statin recipients, as well as to detect the difference in severity of muscle pain and other muscle-related symptoms in atorvastatin or rosuvastatin recipients and among different duration groups. Moreover, a secondary objective was included to assess serum creatinine kinase levels in these statin recipients.

\section{Materials and Methods}

An observational, cross-sectional study was conducted between 1st September 2019 to 31st October 2019 on 80 patients receiving treatment in the Cardiology OPD of Burdwan Medical College and Hospital and who had already received statin therapy for a period of at least one month prior to the commencement of this study. Patients between 18 and 70 years were included from either gender. A literacy bar was set (only those who had attended school up to the $4^{\text {th }}$ standard or higher were included) to ensure comprehensibility, but those with pre-existing myalgia or neuropathy were excluded. Patients were enrolled serially after obtaining informed consent from them in an informed consent form. During the study period, only two members of the statin family, namely atorvastatin and rosuvastatin were being prescribed from the Cardiology OPD of Burdwan Medical College and Hospital. Therefore, patients receiving these two drugs were divided into four groups based on the duration of continuing statin therapy: patients receiving statin for 1 month to 3 months, more than 3 months to 6 months, more than 6 months to 12 months and more than 12 months. Prescribed dose of each drug was noted.

Based on the observations from a previous study $^{15}$, two scores were obtained from two 
different visual analogue scales (VAS) provided to each of the 80 patients. For the VAS myalgia scale, the stem question was "How severe is your muscle pain?"On the other hand, the patientspecific symptoms included focal muscle pain, generalized muscle pain, muscle cramping and muscle weakness. The stem question for the symptom-specific VAS was, "How severe is your symptom?" and each patient was asked to choose the symptom that was most pertinent to him/her. For both VAS, the patient responded by scoring between $0 \mathrm{~mm}$ (complete absence of symptoms) and $100 \mathrm{~mm}$ (maximum intensity for the symptom being evaluated) on a horizontal line.

\section{VAS myalgia: "How severe is your pain?"}

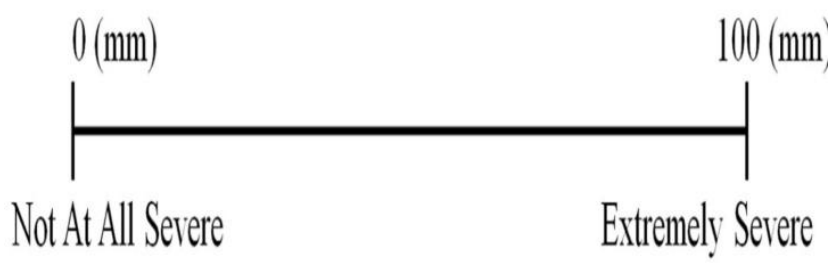

Symptom specific VAS: (Focal muscle pain/ Generalized muscle pain/ Muscle cramping/ Muscle weakness) "How severe is your symptom?"

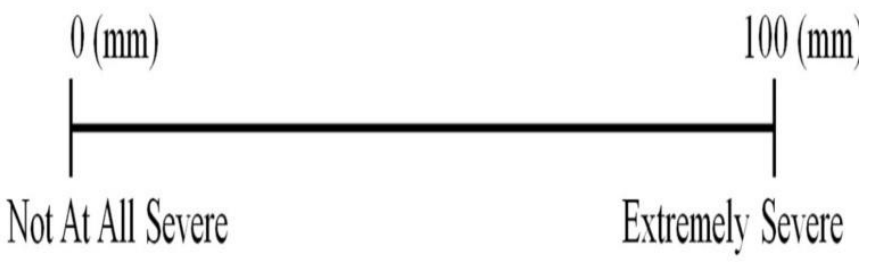

Though serum creatine kinase (CK) levels are not always consistent with myalgia as an elevated level can be found in other conditions as well (including physical exertion), ${ }^{15}$ yet, it is regarded as a significant serum marker of myalgia. Therefore, blood samples were obtained from all the patients to assess serum CK levels. In addition, a lipid profile test was conducted on each blood sample to assess and record the plasma levels of total cholesterol, triglyceride, HDL, LDL and VLDL cholesterol.
Causal relationship between the VAS scores and serum CK levels were assessed using the Naranjo scale.

\section{Statistical Analysis}

Mean values of the two VAS scores (VAS myalgia and symptom-specific VAS) were obtained from the responses of the patients and they were separately compared between the four groups (duration of continuing statin therapy 1-3 months, >3-6 months, >6-12 months and >12 months) using One-way ANOVA. Similarly, these mean values of VAS myalgia scores and symptom-specific VAS scores were compared between the two drugs (atorvastatin and rosuvastatin) using Independent Samples t Test.

It was a part of the statistical analysis plan to obtain a scatter plot to identify any linear relationship between the mean VAS scores and serum CK levels and in case of a linear relationship, calculating a Pearson's product moment correlation coefficient $r$ to determine the strength of correlation.

All statistical tests were performed using IBM SPSS ver. 20.0.

\section{Results}

Baseline characteristics are described in Table 1.0 and 1.1. There was no significant difference between the two groups in terms of age, gender, plasma levels of triglyceride, HDL-C and LDL-C. However, plasma total cholesterol level was significantly lower in rosuvastatin group.

Moreover, the baseline characteristics were similar among the four duration groups as well. (Table 1.1) 


\section{JMSCR Vol||07||Issue||12||Page 104-115||December}

Table 1.0: Baseline characteristics compared between the two statins

\begin{tabular}{|c|c|c|c|c|}
\hline $\begin{array}{l}\text { Baseline } \\
\text { characteristics }\end{array}$ & $\begin{array}{l}\text { Atorvastatin } \\
(\text { Mean } \pm \text { SEM) }\end{array}$ & $\begin{array}{l}\text { Rosuvastatin } \\
(\text { Mean } \pm \text { SEM) }\end{array}$ & $\begin{array}{c}\text { Total } \\
(\text { Mean } \pm \text { SEM })\end{array}$ & P value* \\
\hline Age (Years) & $55.29 \pm 1.59$ & $58.09 \pm 2.42$ & $56.41 \pm 1.36$ & 0.316 \\
\hline Gender & $\begin{array}{c}\mathrm{M}: \mathrm{N}=25,52 \% \\
\mathrm{~F}: \mathrm{N}=23,48 \% \\
\\
\text { (Total }=48)\end{array}$ & $\begin{array}{c}\mathrm{M}: \mathrm{N}=21,65 \% \\
\mathrm{~F}: \mathrm{N}=11,35 \% \\
(\text { Total }=32)\end{array}$ & $\begin{array}{c}\mathrm{M}: \mathrm{N}=46,57.5 \% \\
\mathrm{~F}: \mathrm{N}=34,42.5 \% \\
(\text { Total }=80)\end{array}$ & 0.23 \\
\hline $\begin{array}{l}\text { Total cholesterol } \\
(\mathrm{mg} / \mathrm{dl})\end{array}$ & $216.27 \pm 4.73$ & $202.38+4.26$ & $210.71+3.38$ & 0.043 \\
\hline $\begin{array}{l}\text { Triglyceride } \\
(\mathrm{mg} / \mathrm{dl})\end{array}$ & $119.63 \pm 3.57$ & $111.44 \underline{+3.00}$ & $116.35 \pm 2.48$ & 0.107 \\
\hline HDL-C (mg/dl) & $50.35+0.68$ & $52.63+1.13$ & $51.26+0.62$ & 0.071 \\
\hline LDL-C (mg/dl) & $168.46 \pm 21.21$ & $132.47 \underline{+3.41}$ & $154.06 \pm 12.89$ & 0.173 \\
\hline
\end{tabular}

\section{Table 1.1:}

\begin{tabular}{|c|c|c|c|c|c|c|}
\hline $\begin{array}{l}\text { Baseline } \\
\text { characteristics }\end{array}$ & $\begin{array}{l}\text { 1-3 months } \\
\text { (Mean+SEM) }\end{array}$ & $\begin{array}{l}>3-6 \text { months } \\
\text { (Mean+SEM) }\end{array}$ & $\begin{array}{l}>6-12 \text { months } \\
(\text { Mean } \pm \text { SEM })\end{array}$ & $\begin{array}{l}>12 \text { months } \\
\text { (Mean+SEM) }\end{array}$ & $\begin{array}{c}\text { Total } \\
(\text { Mean+SEM) }\end{array}$ & $\begin{array}{c}\mathrm{P} \\
\text { value* }^{*}\end{array}$ \\
\hline Gender & $\begin{array}{c}M: N=14,54 \% \\
F: N=12,46 \% \\
(\text { Total }=26)\end{array}$ & $\begin{array}{c}M: N=12,63 \% \\
F: N=7,37 \% \\
(\text { Total }=19)\end{array}$ & $\begin{array}{c}M: N=17,71 \% \\
F: N=7,29 \% \\
(\text { Total }=24)\end{array}$ & $\begin{array}{c}M: N=3,27 \% \\
F: N=8,73 \% \\
(\text { Total }=11)\end{array}$ & $\begin{array}{c}M: N=46,57.5 \% \\
F: N=34,42.5 \% \\
(\text { Total }=80)\end{array}$ & 0.1 \\
\hline Total cholesterol & $218.35 \pm 7.23$ & $214.26 \pm 7.51$ & $203.42 \pm 3.80$ & $202.45 \pm 8.09$ & $210.71+3.38$ & 0.25 \\
\hline Triglyceride & $118.15 \pm 5.14$ & $123.79 \pm 6.25$ & $111.96+2.93$ & $108.82+3.68$ & $116.35+2.48$ & 0.213 \\
\hline HDL-C & $51.04 \pm 1.17$ & $50.68 \pm 1.44$ & $51.79 \pm 1.04$ & $51.64 \pm 1.30$ & $51.26 \pm 0.62$ & 0.917 \\
\hline
\end{tabular}

Baseline characteristics compared between the duration groups

$* \mathrm{CI}=95 \%$ and $80 \%$ power

Doses of each drug being received by the patients were recorded and a summary was shown in Table 2.0.

Table 2.0 Doses of each drug received by the patients

\begin{tabular}{|l|c|c|}
\hline Drug & $\begin{array}{c}\text { Dose } \\
\text { (in } \mathrm{mg})\end{array}$ & No.of recipients \\
\hline Atorvastatin & 10 & 21 \\
\hline Rosuvastatin & 40 & 20 \\
\hline & 10 & 7 \\
\hline
\end{tabular}




\section{JMSCR Vol||07||Issue||12||Page 104-115||December}

When the two VAS scores were compared between the two groups of statin recipients, both the VAS myalgia score as well as the symptomspecific VAS score were lower in the rosuvastatin recipients. However, neither of these differences were statistically significant. (Table 3.0) Figure 1.0 and 1.1 show the difference between mean VAS myalgia score and symptom-specific VAS score in the two statin groups.

Table 3.0: Difference of VAS scores between two statin groups

\begin{tabular}{|l|c|c|c|}
\hline & $\begin{array}{c}\text { Atorvastatin } \\
(\text { Mean } \pm \text { SEM) }\end{array}$ & $\begin{array}{c}\text { Rosuvastatin } \\
(\text { Mean } \pm \text { SEM) }\end{array}$ & P value* \\
\hline VAS myalgia score & $16.88 \pm 2.56$ & $11.19 \pm 1.35$ & 0.091 \\
\hline Symptom-specific VAS score & $16.60 \pm 2.53$ & $12.22 \pm 1.49$ & 0.192 \\
\hline
\end{tabular}

$* \mathrm{CI}=95 \%$ and $80 \%$ power

Figure 1.0:

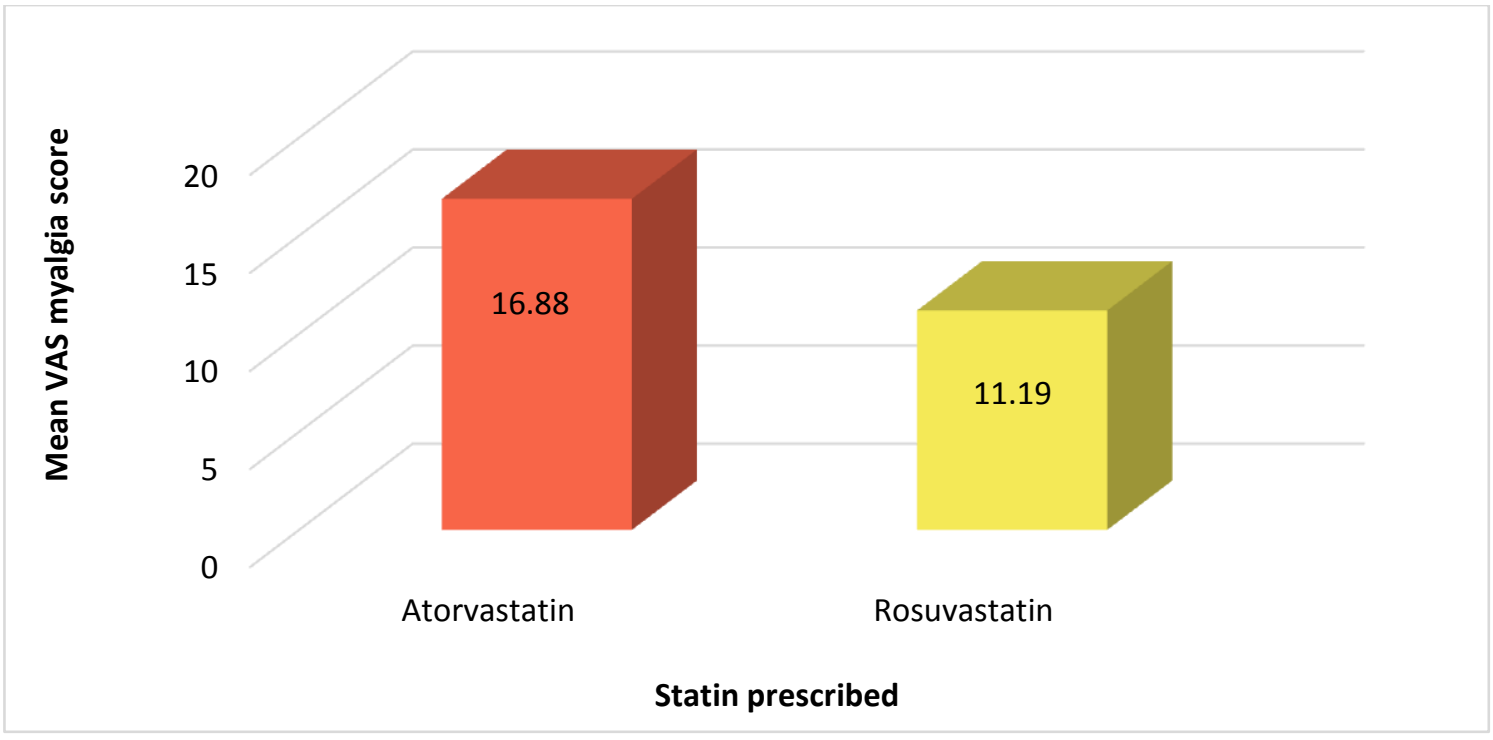

Figure 1.1:

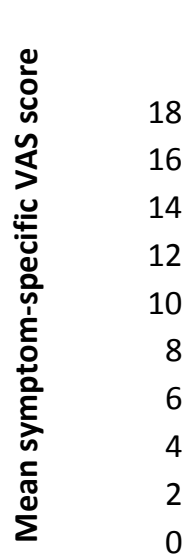

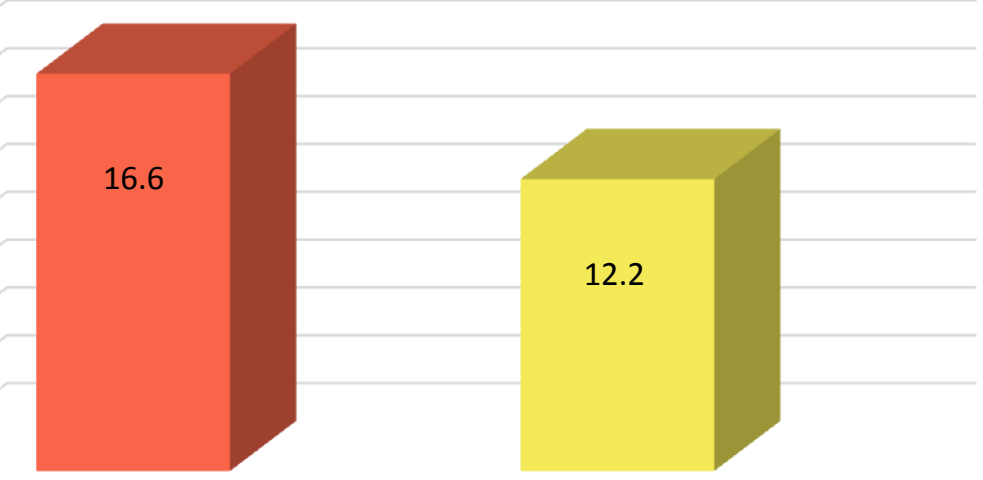

Atorvastain

Rosuvastatin

Statin prescribed 
However, comparison among the four groups based on duration of statin treatment revealed a statistically significant difference in terms of both the VAS scores. (Table 4.0) Highest mean values of both VAS scores were observed in the patients receiving statin for $>12$ months (mean VAS myalgia score was 20.78 and mean symptomspecific VAS score was 32.18). A post hoc analysis revealed that patients who had received statin treatment for $>12$ months had statistically significant differences with all other groups in terms of both the VAS scores. (Table 5.0 and 5.1) These differences were maximum with those who had received statin for 1-3 months only. Figure 2.0 and 2.1 show the mean VAS scores in the four duration groups.

Table 4.0: Difference of VAS scores between the duration of treatment groups

\begin{tabular}{|c|c|c|c|c|c|}
\hline & $\begin{array}{c}\text { 1-3 months } \\
\text { (Mean+SEM) }\end{array}$ & $\begin{array}{l}\text { >3-6 months } \\
\text { (Mean+SEM) }\end{array}$ & $\begin{array}{l}>6-12 \text { months } \\
(\text { Mean } \pm \text { SEM) }\end{array}$ & $\begin{array}{c}>12 \text { months } \\
\text { (Mean+SEM) }\end{array}$ & P value* \\
\hline VAS myalgia score & $7.96 \pm 1.76$ & $10.68 \pm 2.22$ & $14.33 \pm 2.93$ & $20.78 \pm 6.26$ & 0.01 \\
\hline $\begin{array}{l}\text { Symptom-specific } \\
\text { VAS score }\end{array}$ & $8.08 \pm 1.54$ & $10.68 \pm 7.20$ & $15.16 \pm 3.09$ & $32.18 \pm 6.19$ & 0.01 \\
\hline
\end{tabular}

Table 5.0: Post hoc analysis* of VAS myalgia score

\begin{tabular}{|c|c|c|}
\hline Duration group & Mean difference & P value** \\
\hline $1-3$ & 22.49 & 0.01 \\
$>3-6$ & 19.77 & 0.01 \\
$>12$ & & \\
$>6-12$ & 12.83 & 0.048 \\
\hline Bonferroni & & \\
$* * *$ CI=95\% and $80 \%$ power & & \\
\hline
\end{tabular}

Table 5.1 Post hoc analysis* of symptom-specific VAS score

\begin{tabular}{|c|c|c|}
\hline Duration group & Mean difference & P value** \\
\hline $1-3$ & 24.11 & 0.01 \\
$>3-6$ & 21.49 & 0.01 \\
$>12$ & & \\
$>6-12$ & 16.64 & 0.012 \\
\hline *Bonferroni & & \\
$* *$ CI=95\% and $80 \%$ power &
\end{tabular}


Figure 2.0

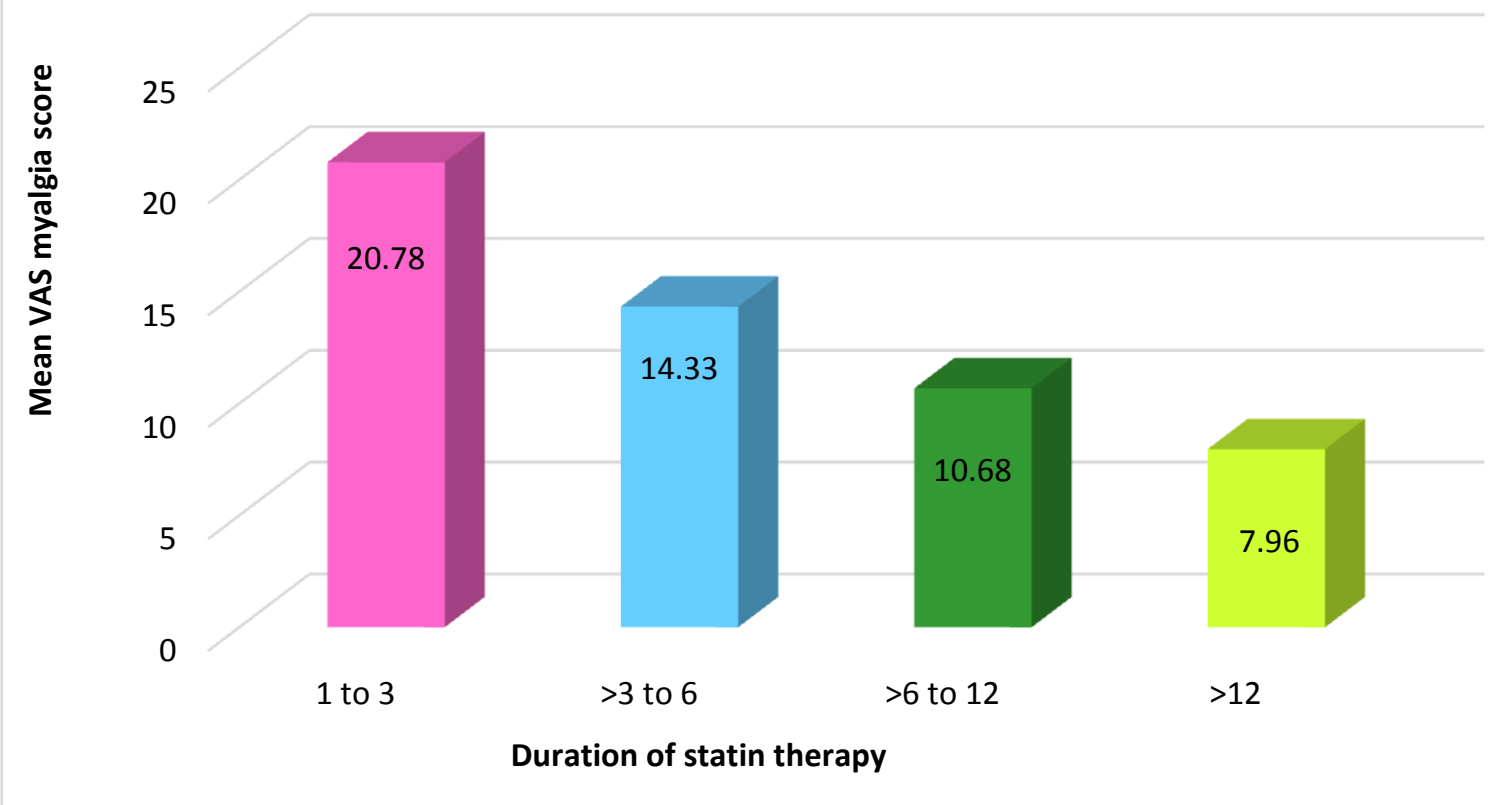

Figure 2.1

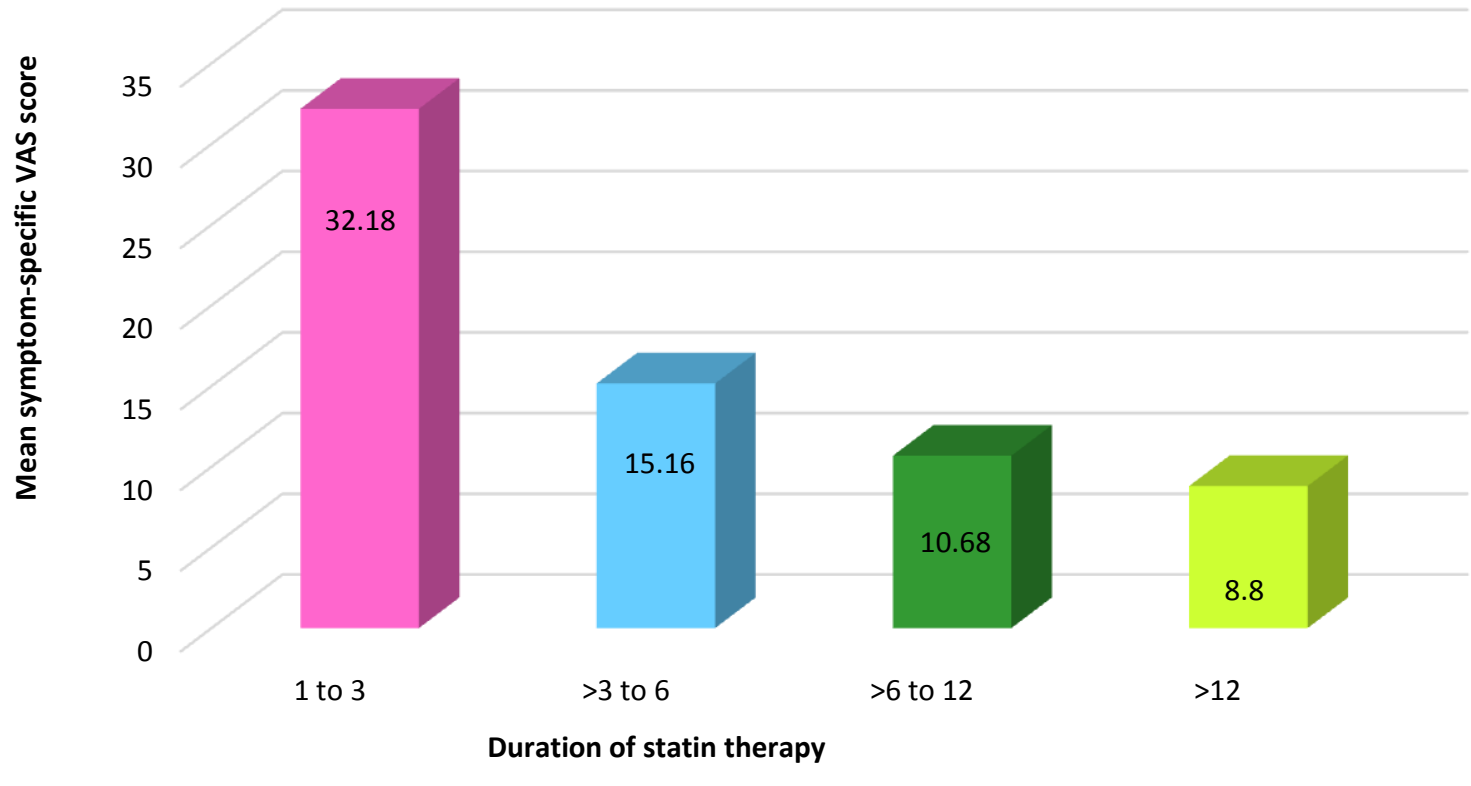

Furthermore, among the four symptoms mentioned in the symptom-specific scale, maximum number of patients $(\mathrm{N}=40,50 \%)$ selected generalized muscle pain as their most pertinent complaint, followed by muscle weakness $(\mathrm{N}=23,29 \%)$, muscle cramping $(\mathrm{N}=10,12 \%)$ and focal muscle pain ( $\mathrm{N}=7,9 \%)$. (Figure 3.0) Among the 7 patients who selected focal muscle pain as their most pertinent complaint, pain in calf muscles $(\mathrm{N}=5,72 \%)$ was more commonly reported than foot pain $(\mathrm{N}=2,28 \%)$. 


\section{JMSCR VoI||07||Issue||12||Page 104-115||December}

Figure 3.0

\section{Reported symptoms}

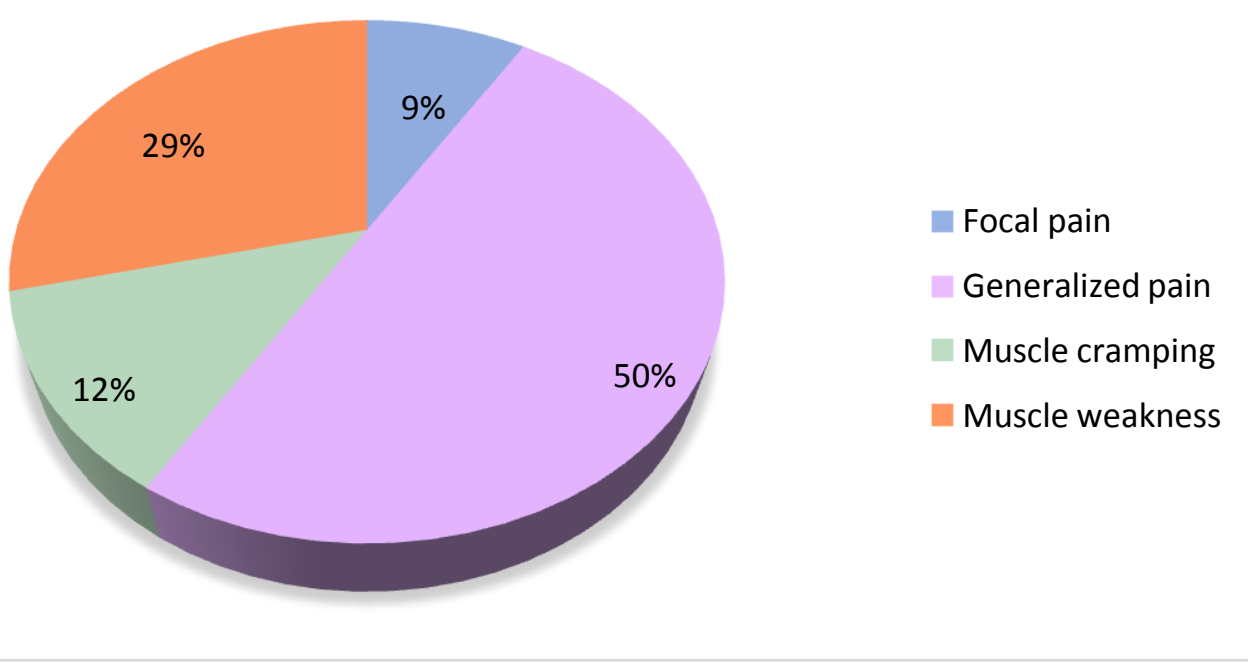

From the scatter plots (Figure 4.0 and 4.1), a linear relationship was observed between serum CK level and each of the two VAS scores. Moreover, the VAS myalgia score $(r=0.768)$ as well as the symptom-specific VAS score $(\mathrm{r}=0.774)$ showed a strongly positive correlation with serum CK levels.

\section{Figure 4.0}

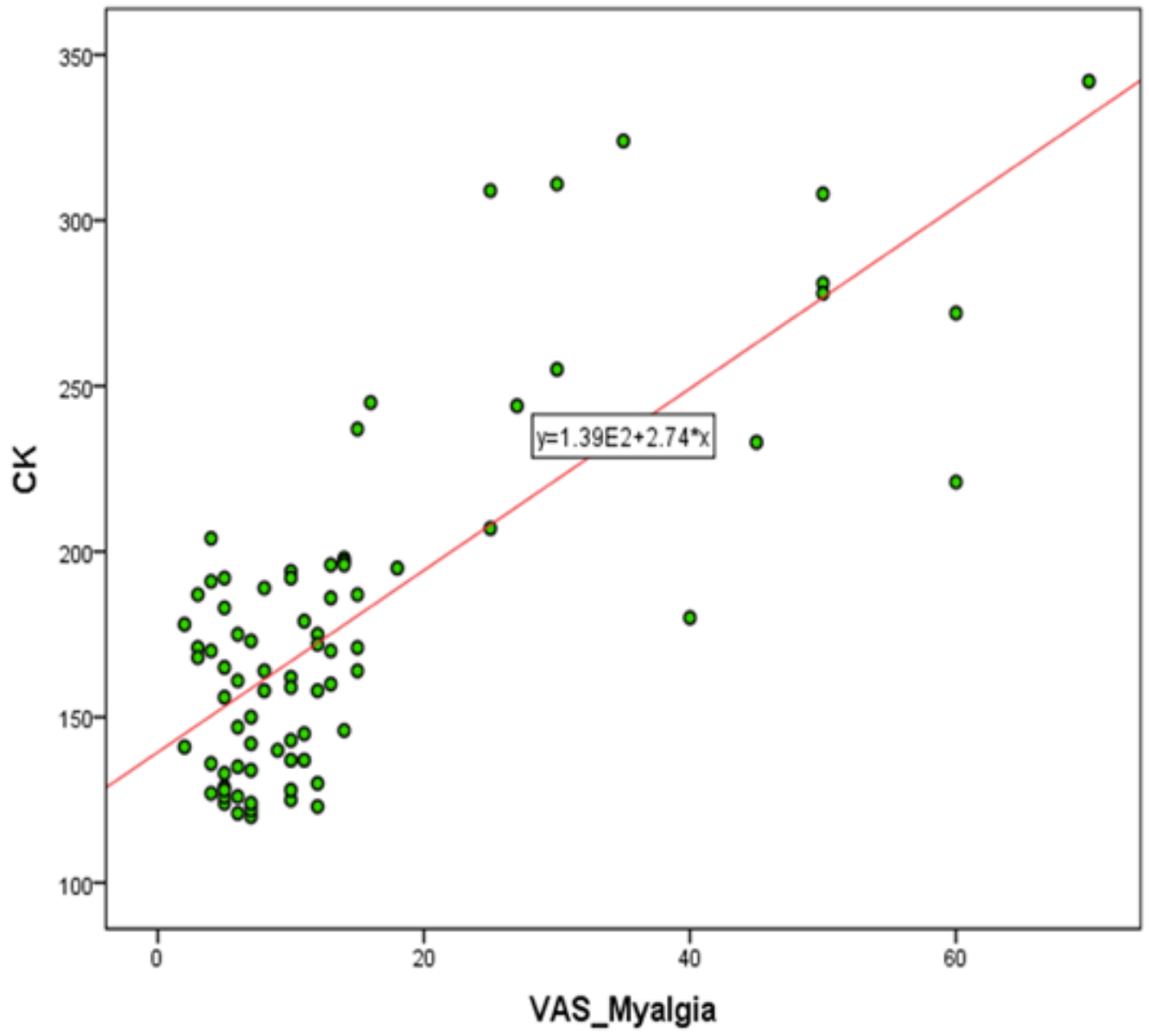


Figure 4.1

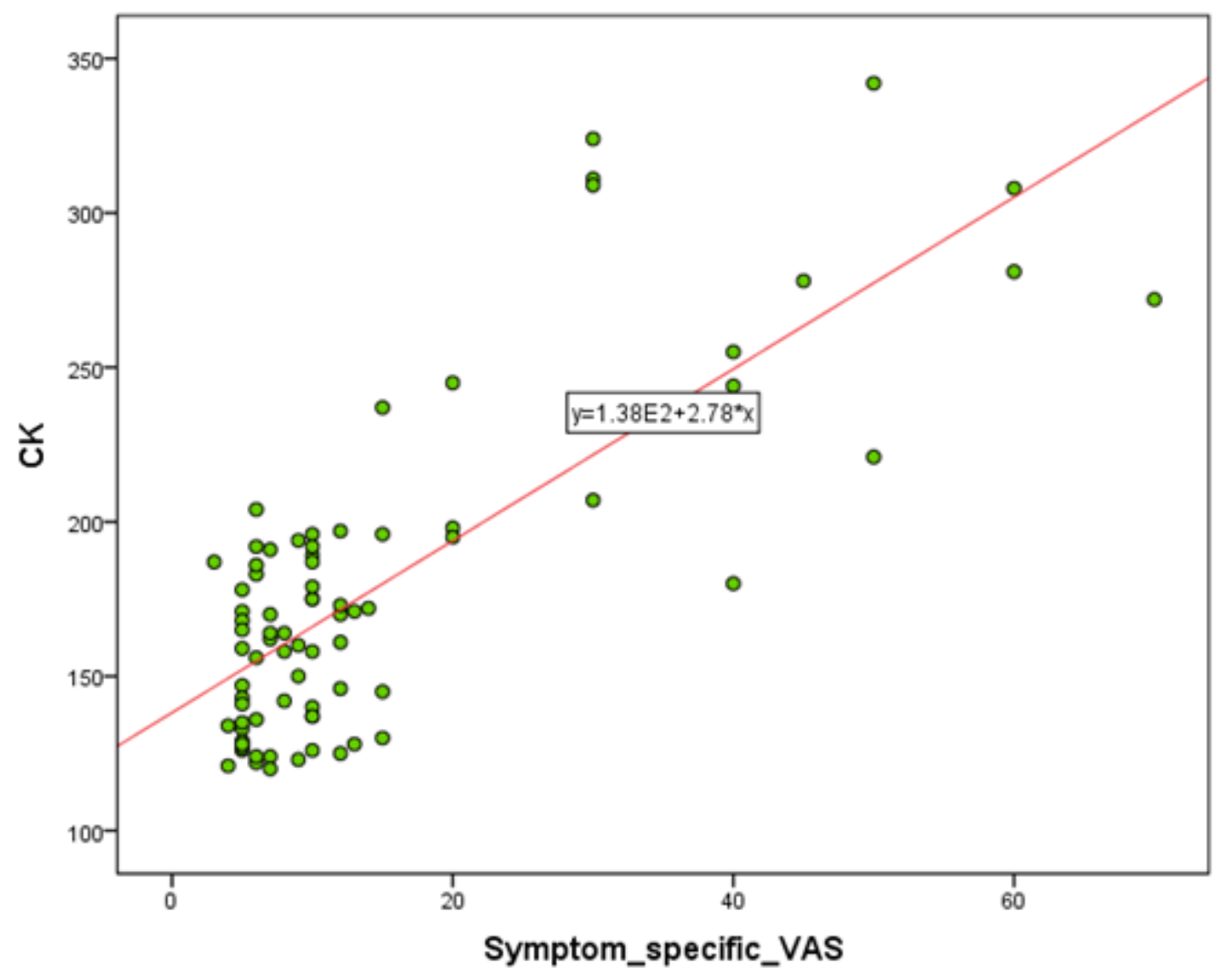

Assessment of causality relationship between statin therapy and myalgia, however, revealed an inclination towards the 'doubtful' category $(\mathrm{N}=69$, $86 \%)$. There were only 11 cases that could achieve a higher category, among which 9 cases (11\%) fell into the 'possible' category and only 2 (3\%) went to 'probable'. (Figure 5.0)

\section{Figure 5.0}

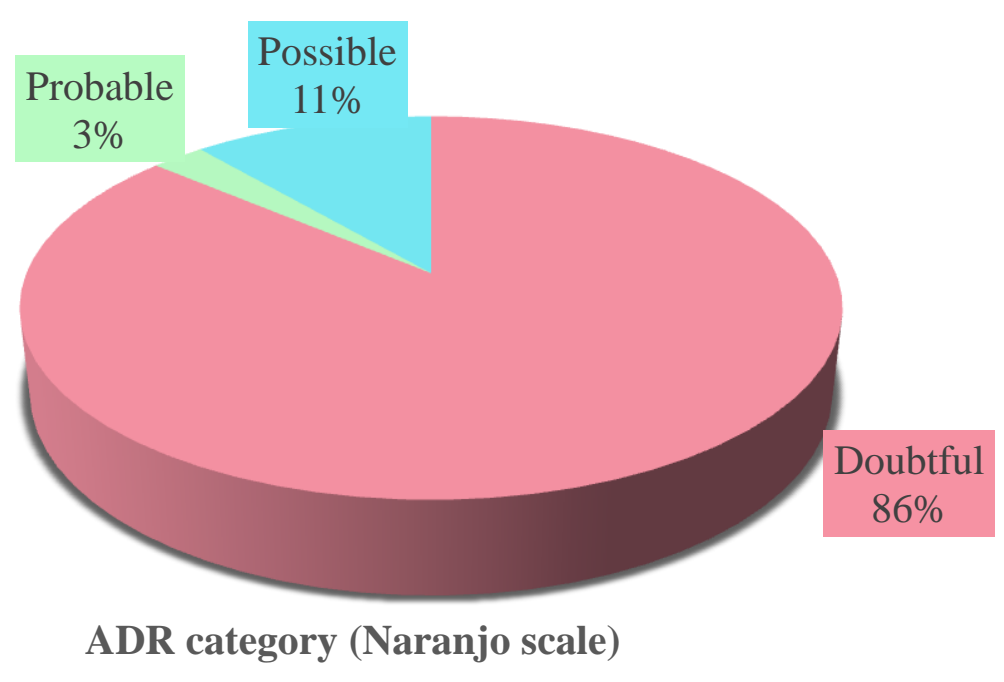




\section{Discussion}

Primary objective of this study was to assess the occurrence of myalgia in statin recipients and two different VAS scores were used for this assessment. Though all 80 patients who were enrolled for this study reported some sort of myalgia or muscle related symptom (lowest score in both VAS scales was 2 and highest was 70), it should be noted that after a causality assessment using the Naranjo scale was performed, majority of them (86\%) ascertained to be 'doubtful'. Only $11(14 \%)$ cases could achieve a higher category and this finding is consistent with the observations of earlier studies ${ }^{15-17}$ that reported $10-15 \%$ of statin users could develop myalgia.

The fact that no significant difference was found between the two statins (atorvastatin and rosuvastatin) in terms of mean VAS scores is consistent with earlier observations. ${ }^{30}$ However, significant difference among the duration groups and mean VAS scores being maximum in patients receiving statins for $>12$ months establish the directly proportional nature of myalgia with duration of statin therapy.

Moreover, a strongly positive correlation between the two VAS scores and serum CK levels denote the possibility that this can be used as a serum marker to diagnose statin-induced myalgia. However, further studies are required on a larger sample size to make any conclusion.

There were certain limitations of this study. For example, a cross-sectional study with a single observation may not be ideal to assess a gradually progressive adverse reaction like statin-induced myalgia. A prospective study with multiple observations could have been more ideal. Another limitation of this cross-sectional study was that, it did not permit us to conduct a dose-based analysis as we received reports of frequent changes in doses during the treatment period. Furthermore, patients were observed during ongoing statin therapy. Therefore, dechallenge and rechallenge of the suspected offender that could establish the causality relationship even better,were impossible.

\section{Conclusion}

Within the limitations of this present study, it was found that atorvastatin and rosuvastatin do not significantly differ from each other in terms of statin-induced myalgia. Moreover, statin-induced myalgia was found to be a gradually progressive adverse reaction and found in maximum intensity among patients who had received statins for more than a year.

\section{Sources of support: Nil \\ Previous presentation or publications: Nil Conflict of interest: Nil}

\section{References}

1. Ardeshna DR, Bob-Manuel T, Nanda A, Sharma A, Paul W, Skelton M. AsianIndians: a review of coronary artery disease in this understudied cohort in the United States. Ann Transl Med. 2018;6:112.

2. Praveen PA, Roy A, Anand K, Lakshmy R, Ruby G, Shah Bet al. Rising prevalence of coronary heart disease (CHD) in urban Delhi, India-results from a repeat crosssectional study. Eur Heart J. 2013;34(abstract suppl):470.

3. Emerging Risk Factors Collaboration, Di Angelantonio E, Sarwar N, Perry P, Kaptoge S, Ray KK et al. Major lipids, apolipoproteins, and risk of vascular disease. JAMA. 2009 Nov 11;302(18):1993-2000.

4. Prospective Studies Collaboration, Lewington S, Whitlock G, Clarke R, Sherliker P, Emberson $\mathrm{J}$ et al. Blood cholesterol and vascular mortality by age, sex, and blood pressure: a metaanalysis of individual data from 61 prospective studies with 55,000 vascular deaths. Lancet. 2007;370:1829-39.

5. Gupta S, Gudapati R, Gaurav K, Bhise M. Emerging risk factors for cardiovascular diseases: Indian context. Indian $\mathbf{J}$ 
Endocrinol Metab. 2013 Sep-Oct; 17(5): 806-14.

6. Gupta R, Gupta R, Guptha S, Sharma KK, Gupta A, Deedwania PC. Regional variations in cardiovascular risk factors in India: India Heart Watch. World J Cardiol. 2012;4:112-20.

7. Sinha RP, Tewari S, Kumar S, Kapoor A, Garg N, Goel PK et al.Comprehensive Lipid Tetrad Index and Lipoprotein(a) as a Marker for Coronary Artery Disease.Indian Heart J 2005; 57: 381-425.

8. Gupta R, Rao RS, Misra A, Sharma SK. Recent Trends in Epidemiology of Dyslipidemias in India. Indian Heart J. 2017;69:382-92.

9. Gupta R, Sharma M, Goyal NK, Bansal P, Lodha S, Sharma KK. Gender differences in seven-year trends in cholesterol lipoproteins and lipids: insights from a hospital database in India. Indian $\mathbf{J}$ Endocrinol Metab. 2016;20:211-8.

10. Gupta R, Sharma KK, Gupta BK, Gupta A, Saboo B, Maheshwari A et al. Geographic epidemiology of cardiometabolic risk factors in urban middle-class residents in India: a cross sectional study. J Global Health. 2015;5:10411.

11. Gupta R, Gupta KD. Coronary heart disease in low socioeconomic status subjects in India: an evolving epidemic. Indian Heart J. 2009;61:358-67.

12. Prabhakaran D, Jeemon P, roy A. Cardiovascular Diseases in India Current Epidemiology and Future Directions. Circulation. 2016;133:1605-20.

13. Catapano AL, Farnier M, Foody JM, Toth PP, Tomassini JE, Brudi $P$ et al.Combination therapy in dyslipidemia: where are we now?Atherosclerosis. 2014 Nov;237(1):319-35.

14. Joy TR, Hegele RA. Narrative Review: Statin-Related Myopathy. Ann Intern Med. 2009;150:858-68.
15. Joy TR, Monjed A, Guang YZ, Hegele RA, McDonald CG, Mahon JL. N-of-1 (Single Patient) Trials for Statin-Related Myalgia. Ann Intern Med. 2014;160:30110.

16. Sewright KA, Clarkson PM, Thompson PD. Statin Myopathy: Incidence, Risk Factors, and Pathophysiology. Current Atherosclerosis Reports. 2007;9:389-96.

17. Sathavism S. Statin induced myotoxicity. E J Intern Med. 2012;23:317-24.

18. Urso ML, Clarkson PM, Hittel D, Hoffman EP, Thompson PD. Changes in ubiquitin proteasome pathway gene expression in skeletal muscle with exercise and statins. Arterioscler Thromb Vasc Biol 2005, 25:2560-6.

19. Jacobson TA. Statin safety. Lessons from new drug applications for marketed statins. Am J Cardiol 2006, 97(8A):44C-51C.

20. Thompson PD, Clarkson P, Karas RH. Statin-associated myopathy. JAMA 2003, 289:1681-90.

21. Kashani A, Phillips CO, Foody JM, Wang Y, Mangalmurti S, Ko DT et al. Risks associated with statin therapy: a systematic overview of randomized clinical trials. Circulation 2006, 114:2788-97.

22. Thavendiranathan P, Bagai A, Brookhart MA, Choudhry NK. Primary prevention of cardiovascular diseases with statin therapy: a meta-analysis of randomized controlled trials. Arch Intern Med 2006, 166:230713.

23. Hansen KE, Hildebrand JP, Ferguson EE, Stein JH: Outcomes in 45 patients with statin-associated myopathy. Arch Intern Med 2005, 165:2671-6.

24. Talbert RL. Safety issues with statin therapy. J Am Pharm Assoc 2006, 46:47988.

25. Pasternak RC, Smith SC Jr, Bairey-Merz CN, Grundy SM, Cleeman JI, Lenfant C, American College of Cardiology. ACC/AHA/NHLBI clinical advisory on 
the use and safety of statins. J Am Coll Cardiol. 2002;40:567-72.

26. Bays H. Statin safety: an overview and assessment of the data-2005. Am J Cardiol. 2006;97:6C-26C.

27. Law M, Rudnicka AR. Statin safety: a systematic review. Am J Cardiol. 2006; 97:52C-60C.

28. Collins R, Reith C, Emberson J, Armitage $\mathrm{J}$, Baignet $\mathrm{C}$, Blackwell $\mathrm{L}$ et al. Interpretation of the evidence for the efficacy and safety of statin therapy. Lancet. 2016; 388: 2532-6.

29. Parker BA, Capizzi JA, Grimaldi AS, Clarkson PM, Cole SM, Keadle J et al. Effect of statins on skeletal muscle function. Circulation 2013; 127: 96-103.

30. Berne C, Siweret-Delle A. Comparison of rosuvastatin and atorvastatin for lipid lowering in patients with type 2 diabetes mellitus: results from the URANUS study.

Cardiovasc Diabetol. 2005; 4: 7. 